\title{
DIVERSIDADE GENÉTICA DE SELEÇÕES DE GOIABEIRAS CORTIBEL ${ }^{1}$
}

\author{
SARA MORRA COSER ${ }^{2}$, MARCIA FLORES DA SILVA FERREIRA ${ }^{3}$, \\ ADÉSIO FERREIRA ${ }^{4}$, SÉRGIO HENRIQUES SARAIVA ${ }^{5}$
}

RESUMO- O Brasil é um dos maiores produtores de goiaba, Psidium guajava L., do mundo. Pomares de propagação seminal, devido à polinização cruzada, apresentam ampla variabilidade, permitindo a seleção de genótipos ao melhoramento. O objetivo deste trabalho foi estudar a diversidade genética de genótipos de goiabeiras selecionadas em pomar de origem seminal (denominadas Cortibel de I a XIII) e compará-las às cultivares Paluma e Pedro Sato, e ao genótipo Roxa, quanto a características morfológicas e de qualidade de frutos. Verificou-se divergência entre os genótipos Cortibel. A Cortibel I, de polpa vermelha, foi o genótipo mais divergente, exibindo o melhor desempenho para as características de frutos. Os genótipos CVIII e CIV apresentaram os melhores desempenhos dentre os genótipos de polpa clara. As seleções de Cortibel apresentaram desempenho semelhante a cultivares comerciais para a qualidade do fruto, sendo bons materiais para o uso como novas cultivares ou para hibridações em programas de melhoramento.

Termos para indexação: Psidium guajava; melhoramento de plantas; qualidade de frutos; descritores morfológicos.

\section{GENETIC DIVERSITY IN CORTIBEL GUAVA SELECTIONS}

\begin{abstract}
Brazil is one of the largest producers of guava, Psidium guajava L., of the world. Orchards from seminal propagation, owing to cross-pollination, result in large variability, allowing the selection of genotypes for crop improvement. The aim of this essay was to study the genetic diversity of genotypes selected from seminal origin orchard (named Cortibel I to XIII) and compare them to Paluma and Pedro Sato and Roxa genotype (purchased in nursery), by morphological and quality of fruit characteristics. There was divergence between Cortibel selections. Cortibel I was the most divergent between red pulp genotypes and between all the others, showing the best performance for fruit characteristics. CVIII and CIV genotypes obtained the best performance between light pulp genotypes. Cortibel selections presented similar performance about fruit quality to commercial crops, providing good material for use as new cultivars or for hybridizations in breeding programs.
\end{abstract}

Index terms: Psidium guajava; plant breeding; fruit quality; morphological descriptors.

1(Trabalho 085-13). Recebido em: 28-02-2013. Aceito para publicação em: 13-02-2014.

${ }^{2}$ Doutoranda em Genética e Melhoramento, Departamento de Fitotecnia, Universidade Federal de Viçosa, Av. PH Rolfs, Campus Viçosa / MG, CEP: 36570-000. E-mail: cosersm@gmail.com

${ }^{3}$ Prof. Dra. Genética Vegetal, CCA/UFES. E-mail: marcia.ferreira@ufes.br

${ }^{4}$ Prof. Dr. Genética e Melhoramento, CCA/UFES. E-mail: adesioferreira@gmail.com

${ }^{5}$ Prof. Dr. Engenharia de Alimentos, CCA/UFES. E-mail: sergio@cca.ufes.br 


\section{INTRODUÇÃO}

O Brasil é um dos principais países produtores de frutas do mundo estando entre os dez maiores produtores de goiaba (Psidium guajava L.). Cerca de $70 \%$ das goiabeiras cultivadas no País são da cultivar Paluma (PEREIRA; KAVATI, 2011), caracterizando a vulnerabilidade genética da cultura e pouco uso da variabilidade da espécie.

A polinização cruzada é a forma reprodutiva mais frequente e eficiente na produção de frutos em P. guajava (ALVES; FREITAS, 2007). Embora a maioria dos pomares seja originada por propagação vegetativa, também são encontrados pomares estabelecidos por propagação seminal. Este fato, aliado ao modo reprodutivo da espécie, resulta em heterogeneidade das goiabeiras no pomar, nas características dos frutos e das plantas, possibilitando a seleção de genótipos para o melhoramento da cultura (LOZANO et al., 2009; NIMISHA et al., 2013).

Estudos de diversidade genética e caracterização de germoplasma geram orientações aos melhoristas de plantas. Em espécies perenes, como $P$. guajava, podem ser realizados com base em descritores morfológicos e agronômicos (SANTOS et al., 2010), características diretamente relacionadas à produção e ao mercado. Também características físico-químicas dos frutos em $P$. guajava são utilizadas, pois estão relacionadas à qualidade do fruto e às exigências do mercado consumidor, sendo já relatada a existência de variação entre cultivares (LIMA et al., 2002).

O objetivo deste trabalho foi avaliar a diversidade genética de genótipos de goiabeiras selecionadas em pomar de origem seminal e comparálas às cultivares Paluma e Pedro Sato e ao genótipo Roxa, por meio de características morfológicas e de qualidade de frutos, visando a orientar programas de melhoramento.

\section{MATERIAL E MÉTODOS}

Foram estudados 16 genótipos de $P$. guajava L., sendo duas cultivares (Paluma e Pedro Sato); 13 genótipos pré-selecionados em pomar de polinização aberta no município de Santa Teresa - ES ('Cortibel I', II, III, IV, V, VI, VII, VIII, IX, X, XI, XII e XIII); e um genótipo adquirido em viveiro (Roxa).

Para a avaliação das características de frutos, estes foram colhidos na safra de 2010-2011, estando as plantas com idade entre 7 e 8 anos, cultivadas em espaçamento de $5 \times 4$ metros. Como indicativo do ponto de maturação, foi considerada a cor da casca, segundo Azzolini et al. (2004). Cinco frutos por árvore foram colhidos, de duas árvores por genótipo, em delineamento inteiramente casualizado, totalizando duas repetições. Nestes genótipos, foram avaliadas 14 características quantitativas de frutos, sendo nove métricas e cinco de qualidade dos frutos. As métricas foram: massa ( $\mathrm{M}$ em gramas), comprimento ( $\mathrm{C}$ em centímetros), diâmetro total (Dt em centímetros), diâmetro interno (Di), relação Dt/ Di, massa da polpa (MP), número de lóculos (NL), massa de sementes (MS) e número de sementes (NS). As características de qualidade foram: $\mathrm{pH}$, sólidos solúveis totais (SST), acidez titulável (AT), umidade (U) e a relação SST/AT. Para os genótipos CIII e CIX, não foram avaliadas características de qualidade. Além destas, cinco características multicategóricas também foram avaliadas: formato do fruto, forma da base do pedúnculo, coloração externa, textura e coloração do mesocarpo, de acordo com descritores da cultura.

Os dados quantitativos obtidos foram submetidos à análise de variância com testemunhas adicionais (foram testemunhas os genótipos Paluma, Pedro Sato e Roxa). Posteriormente, foi realizado o teste de Dunnett, a 5\% de probabilidade. Os dados multicategóricas foram submetidos à análise descritiva gráfica. Para as características quantitativas, foi obtida a Distância Euclidiana Média Padronizada e, posteriormente, efetuados os métodos de agrupamento de otimização de Tocher e o método hierárquico de Ligação Média entre Grupo ("Unweighted Pair Group Method with Arithmetic Mean" - UPGMA), seguidos da análise de componentes principais (ACP). Todas as análises foram efetuadas no programa Genes (CRUZ, 2006).

\section{RESULTADOS E DISCUSSÃO}

Pela análise de variância, verificouse significância para as características massa, comprimento, diâmetro total, relação $\mathrm{Dt} / \mathrm{Di}$, $\mathrm{pH}$ e relação SST/AT. Foi possível observar diferença entre os contrastes das médias para estas características, destacando-se os genótipos Cortibel em relação ao grupo de testemunhas (Tabela 1).

Nas características massa, comprimento e diâmetro total, os genótipos CI e CIII apresentaram as performances superior e inferior, respectivamente, em relação às testemunhas, demonstrando o potencial genético do genótipo CI, para uso em melhoramento, e a variabilidade entre os genótipos Cortibel. Os demais genótipos Cortibel, com exceção de CIII, apresentaram comportamento semelhante às cultivares, portanto dentro do padrão comercial, 
sendo também genótipos potenciais para programas de melhoramento.

A relação Dt/Di fornece uma estimativa do rendimento de polpa, de forma que quanto maior a relação, maior o rendimento. $\mathrm{O}$ genótipo CIX apresentou a maior relação, diferindo das testemunhas, seguido por $\mathrm{CI}$ e $\mathrm{CV}$, que foram superiores a Paluma e Pedro Sato, e similares à Roxa. Os genótipos CV, CVII e CIX apresentaram o menor número de sementes, sendo inferiores às cultivares e semelhantes à Roxa. Para as demais características (número de lóculos, massa da polpa e massa de sementes), todas as Cortibel apresentaram comportamento semelhante aos padrões comerciais.

Frutos médios de 100 a 300 g, com poucas sementes e diâmetro a partir de sete centímetros, são os critérios de seleção em programas de melhoramento (PEREIRA; NACHTIGAL, 2009). Os genótipos pré-selecionados de Cortibel, com exceção de CIII, ficaram dentro desses critérios. Portanto, esses genótipos são potenciais para hibridações em programas de melhoramento por agregarem características exigidas pelo mercado.

Quanto às características de qualidade, o caráter SST fornece um indicativo sobre a quantidade de açúcares nos frutos (MANICA et al., 1998), portanto importante na qualidade organoléptica destes, sendo desejáveis valores acima de $10^{\circ}$ Brix. Essa característica variou de 7,4 a $11,4^{\circ}$ Brix e não apresentou diferença significativa dos genótipos Cortibel, quando comparados aos comerciais, evidenciando padrões comerciais destas características nos genótipos Cortibel.

A acidez, avaliada por meio da presença de ácidos orgânicos expressos em ácido cítrico, é de grande importância, pois fornece dados relacionados ao estado de conservação de um produto alimentício (BRUNINI et al., 2003). Essa característica (AT) não apresentou diferença entre os materiais avaliados, e os valores obtidos ficaram dentro dos parâmetros exigidos.

$\mathrm{O} \mathrm{pH}$ é uma característica importante na qualidade de frutos, pois condições ótimas para formação de gel em doces em massa e geleias ocorrem em valores específicos de $\mathrm{pH}$ da polpa. Os valores encontrados nos genótipos avaliados estão dentro dos limites citados por Yusof (1990) para diversas variedades de goiabeira, 3.0 a 4.1, com exceção do genótipo CIV, que apresentou o valor de pH mais elevado em relação às cultivares $(4,4)$ e em relação aos padrões para processamento industrial.

A relação SST/AT é um dos parâmetros mais importantes quanto à qualidade dos frutos e a destinação comercial, pois de acordo com Krolow e Schwengber (2007), confere aos frutos melhor equilíbrio entre o doce e o ácido, resultando em sabor mais agradável, tornando-os mais atrativos. Frutos com relação SST/AT superior a 11,7 são considerados ideais para o comércio (PEREIRA; NACHTIGAL, 2002). Todos os genótipos avaliados tiveram valor superior, sendo o menor valor encontrado de 14,81. Quatro genótipos de Cortibel (CIV, CV, CVII e CXII) tiveram valores superiores às testemunhas.

Os resultados encontrados neste trabalho de pH, AT, SST, relação SST/AT e umidade estão dentro dos padrões encontrados por Lima et al. (2002) e Manica (1998), ao caracterizarem físicoquimicamente cultivares e seleções de P. guajava.

Para a maior parte das Cortibel avaliadas, tem-se que todos os parâmetros físico-químicos analisados atendem aos Padrões de Identidade e Qualidade para polpa de goiaba, estabelecido pelo Ministério da Agricultura, Pecuária e Abastecimento, que exige teores de sólidos solúveis mínimo de 7, $0^{\circ}$ Brix; pH entre 3,5 a 4,2; e acidez total titulável expressa em ácido cítrico, mínimo de $0,40 \mathrm{~g} / 100 \mathrm{~g}$. Esse fato, mais uma vez, reforça o destaque desses genótipos como fonte de variação para o cultivo e os programas de melhoramento.

Outra forma de caracterizar genótipos é pelo uso de dados morfológicos qualitativos. As características multicategóricas de frutos analisadas permitiram visualizar grande variabilidade nessas características entre os genótipos (Figura 1). Também foi verificada variação, embora pequena, das características observadas nos diferentes frutos das repetições por genótipo.

Quanto ao formato dos frutos, a maioria dos genótipos apresentou formato arredondado e pera. As cultivares Paluma e Pedro Sato apresentaram $50 \%$ de seus frutos de cada tipo: arredondado e pera. Os genótipos CVI, CVII e CVIII apresentaram exclusivamente formato pera. As Cortibel IV, V, IX, XI e o genótipo Roxa apresentaram três classes de frutos: arredondados, pera e ovoides, enquanto as seleções CI e CX apresentaram alguns formatos de frutos não representados entre os descritores da cultura. Essa variação no formato dos frutos dentro do mesmo genótipo é comum e relatada na literatura (SANABRIA et al., 2006; NIMISHA et al., 2013). De acordo com Pereira e Nachtigal (2002), o formato de fruto mais apreciado pelo mercado é o formato ovoide. Dentre os genótipos, 60\% apresentaram frutos ovoides.

Quanto à característica pedúnculo, a maior parte dos genótipos apresentou formato arredondado, seguido pelo truncado. Somente os genótipos CIII e CXIII apresentaram maior parte de seus frutos com 
formato do pedúnculo amplamente arredondado, e o genótipo CI apresentou frutos com as cinco classes descritas, com predominância do formato truncado.

A coloração externa (casca) foi amarela para a maioria dos genótipos, e suas variações de pálido a escuro, com exceção de Pedro Sato, que apresentou coloração verde. Os genótipos CI, CIII, CV, CVII, CXI e Roxa apresentaram outras colorações não relatadas entre os descritores. Pereira e Nachtigal (2002) destacaram que frutos de coloração verdeamarelada ou amarela, quando maduros, são mais apreciados comercialmente.

A textura teve a menor variação, sendo a maioria dos genótipos de textura lisa e semiáspera. A seleção CV teve somente frutos lisos, e a CIX, somente semiásperos. A cultivar Pedro Sato apresentou frutos ásperos, porém em minoria.

A coloração do mesocarpo é uma importante característica para a comercialização. Segundo Pereira e Nachtigal (2002), frutos de polpa rosada ou avermelhada são preferidos tanto para a indústria como para o consumo in natura no mercado nacional. Essa característica foi bastante variável entre os genótipos. A maioria apresentou coloração com variações dos tons de rosa, incluindo os comerciais Paluma e Pedro Sato. Os genótipos Cortibel IV, VIII e XII apresentaram coloração de polpa bege, sendo, portanto, indicadas para o mercado externo. CV, CVI, CVII e CXI variaram em tons de rosa, no entanto com categorias laranja rosados. Como o nome sugere, o genótipo comercial Roxa apresentou coloração do mesocarpo roxa.

Diferentes análises de agrupamento para os dados morfológicos e de qualidade de frutos foram realizadas (Tabela 2 e Figura 2). O agrupamento pela técnica de Tocher proporcionou a formação de dois grupos: o primeiro grupo constituído por todos os genótipos, com exceção de CI, que formou o grupo II. Tal fato reflete a grande divergência e destaque do genótipo CI em relação aos demais, e também a semelhança das Cortibel em relação aos genótipos cultivados, todos agrupados no grupo I, com potencial, em muitas características desejadas, para hibridação. Em uma análise posterior, este grupo foi desmembrado em cinco subgrupos, revelando variabilidade entre esses materiais.

Nestes novos grupos, os genótipos CIV, CV e Roxa formaram grupos isolados e CII e CVIII agruparam-se. Os demais genótipos de Cortibel permaneceram agrupados com as cultivares Paluma e Pedro Sato. Esse resultado mostra divergência entre essas seleções, porém com semelhança a genótipos já cultivados para características superiores, fornecendo bons materiais para serem utilizados como novas cultivares ou em programas de melhoramento para hibridações.
O agrupamento UPGMA, para as mesmas características, apresentou correlação cofenética de 0,88 , representando o bom ajuste da matriz de dissimilaridade e a formação do agrupamento. Os genótipos mais divergentes foram CI e CII, com 2,13 de distância, e os mais similares, CVI e CXII, com 0,53 de distância. Esse método de agrupamento corroborou os resultados encontrados pelo método de Tocher, com exceção da entrada no genótipo CVI no segundo agrupamento com CII e CVIII. Estabelecendo ponto de corte a $50 \%$ do nível máximo de fusão, é possível verificar a formação de seis grupos (Figura 2): G1, G2, G3, G4, G5 e G6, em que CI também foi o genótipo mais divergente entre os materiais.

Os genótipos CIV e CV também merecem destaque por apresentarem características dentro dos padrões de mercado, aliadas à divergência em relação aos demais genótipos. Os genótipos CVIII e CIV tiveram melhores desempenhos dentre os genótipos de polpa clara.

Coser et al. (2012), mostraram divergência molecular, obtidas por microssatélites, e também morfológicas, para caracteres agronômicos de frutos, entre os genótipos Cortibel e diferentes cultivares brasileiras e também entre os genótipos Cortibel, embora menor em relação às cultivares, reforçando a relevância desses genótipos para uso em programas de hibridação e melhoramento da espécie.

Os resultados da ACP evidenciam que os três primeiros componentes envolveram mais de $95 \%$ da variação total disponível, sendo, portanto, seu uso satisfatório em estudos da divergência genética. Para CP1, os caracteres massa (M - 0,4632), diâmetro total (Dt - 0,4622), comprimento (C - 0,4451), diâmetro interno (Di - 0,4139) e massa da polpa (MP - 0,4006) deram valores altos e próximos de coeficientes de ponderação, explicando 65,02\% da variação; assim, todos os caracteres são considerados importantes no estudo. Ainda, para CP2 e CP3, os caracteres Dt/Di e NL foram os mais importantes, com 0,6544 e -0,5789 em CP2 e 0,4805 e 0,7946 em CP3, respectivamente.

A análise em diversidade e em estudos de caracterização permite a identificação de genótipos para suprir demandas do mercado e fornecer novas opções de cultivos, diversificando a cultura e a produção. Santos et al. (2011), ao avaliarem a diversidade genética baseada em características químicas e agronômicas de frutos entre genótipos de P. guajava coletados no Brasil, encontraram acessos divergentes com alto teor de compostos nutricionais para o desenvolvimento de novas cultivares. Genótipos de destaque também foram encontrados neste trabalho para utilização em futuros programas de melhoramento. 


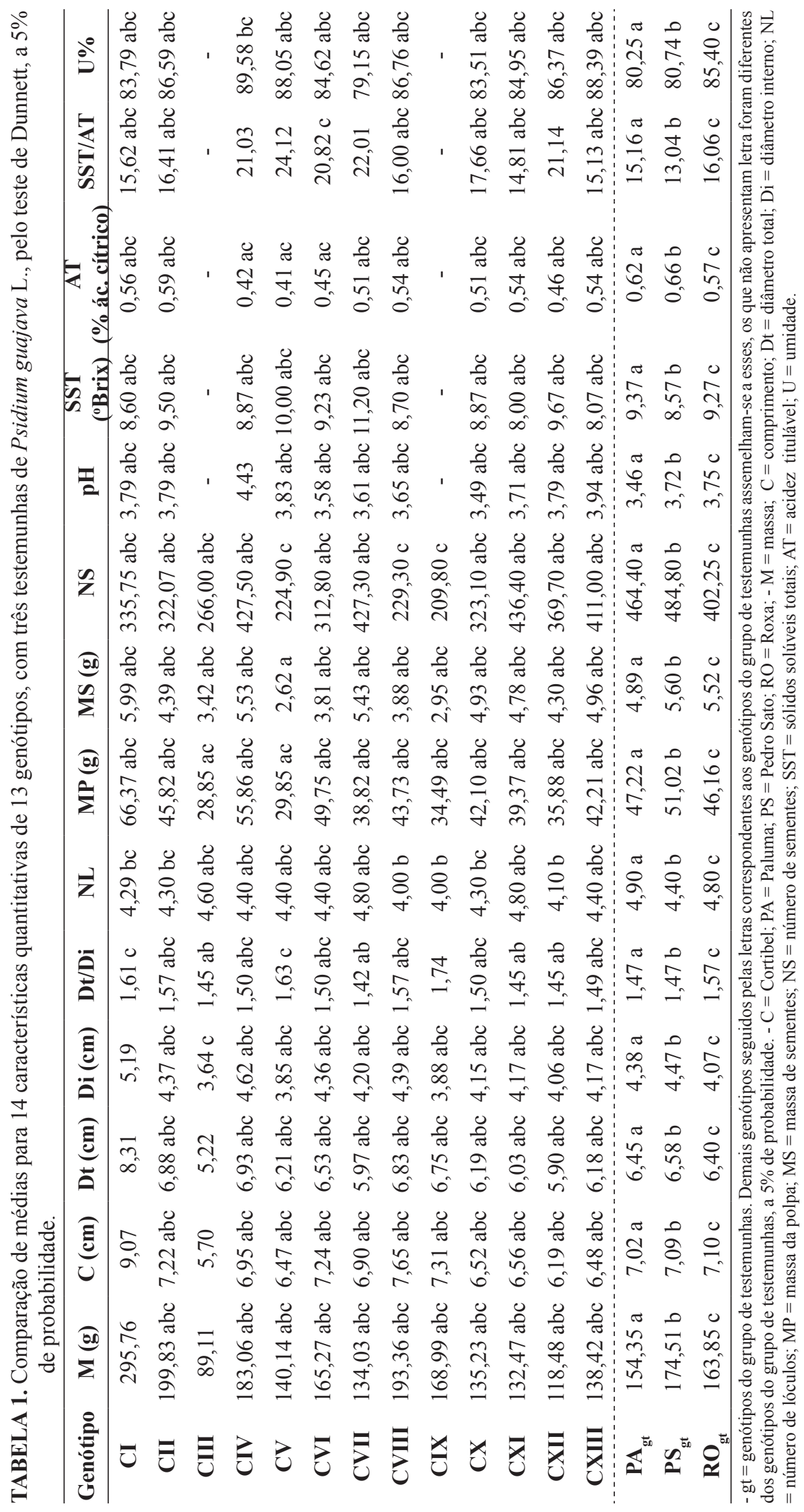




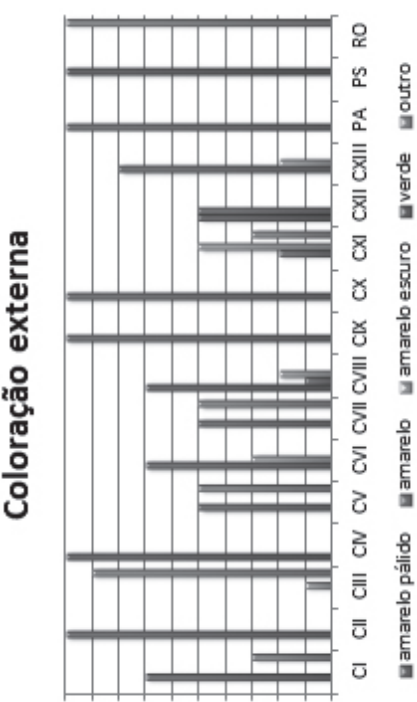

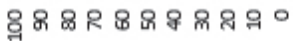

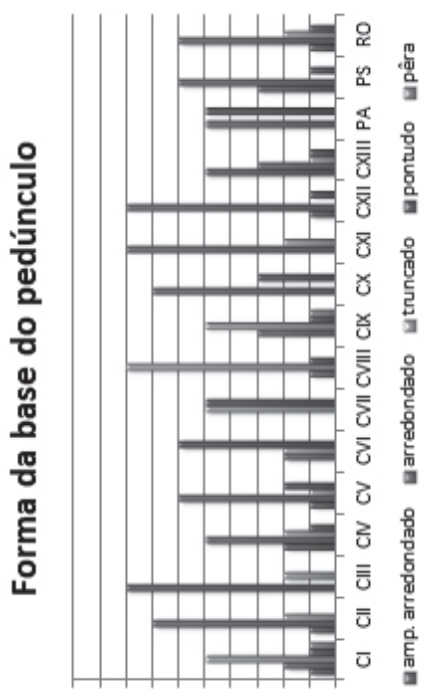

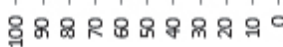

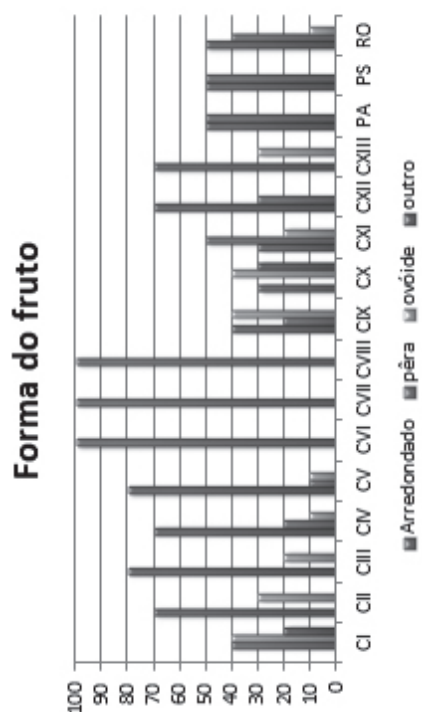

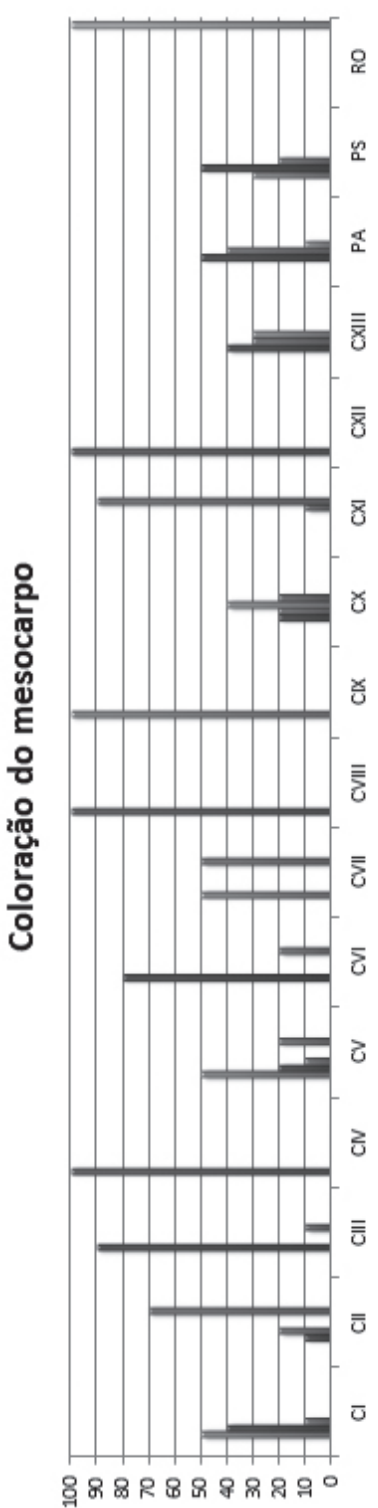

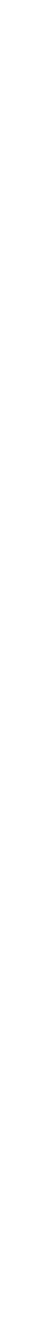

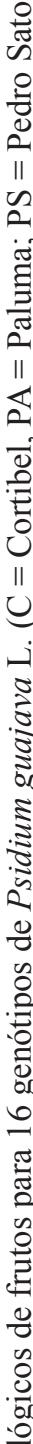

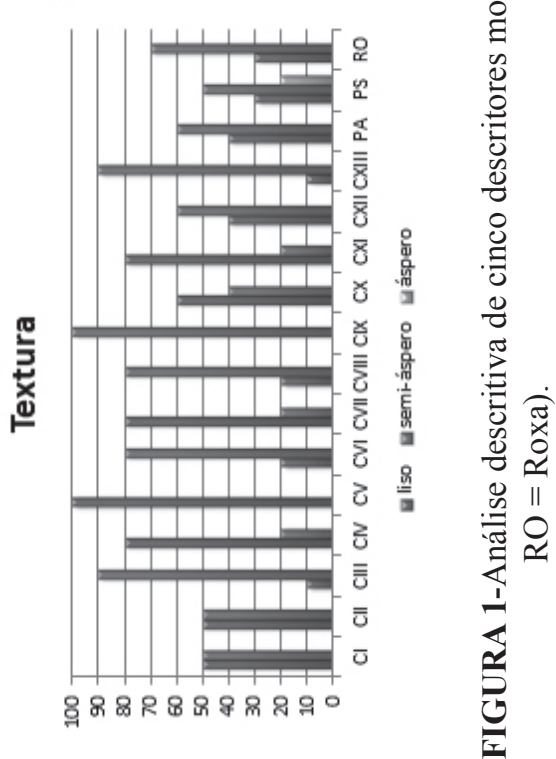


TABELA 2- Grupos e subgrupos para 14 genótipos de Psidium guajava quanto a características quantitativas de frutos, pelo método de Tocher.

\begin{tabular}{cc}
\hline Grupo & Genótipos \\
\hline I & CII, CIV, CV, CVI, CVII, CVIII, CX, CXI, CXII, CXIII, PA, PS e RO \\
II & CI \\
\hline Subgrupo & Genótipos \\
\hline I.I & CVI, CVII, CX, CXI, CXII, CXIII, PA e PS \\
I.II & CII e CVIII \\
I.III & CIV \\
I.IV & RO \\
I.V & CV \\
\hline
\end{tabular}

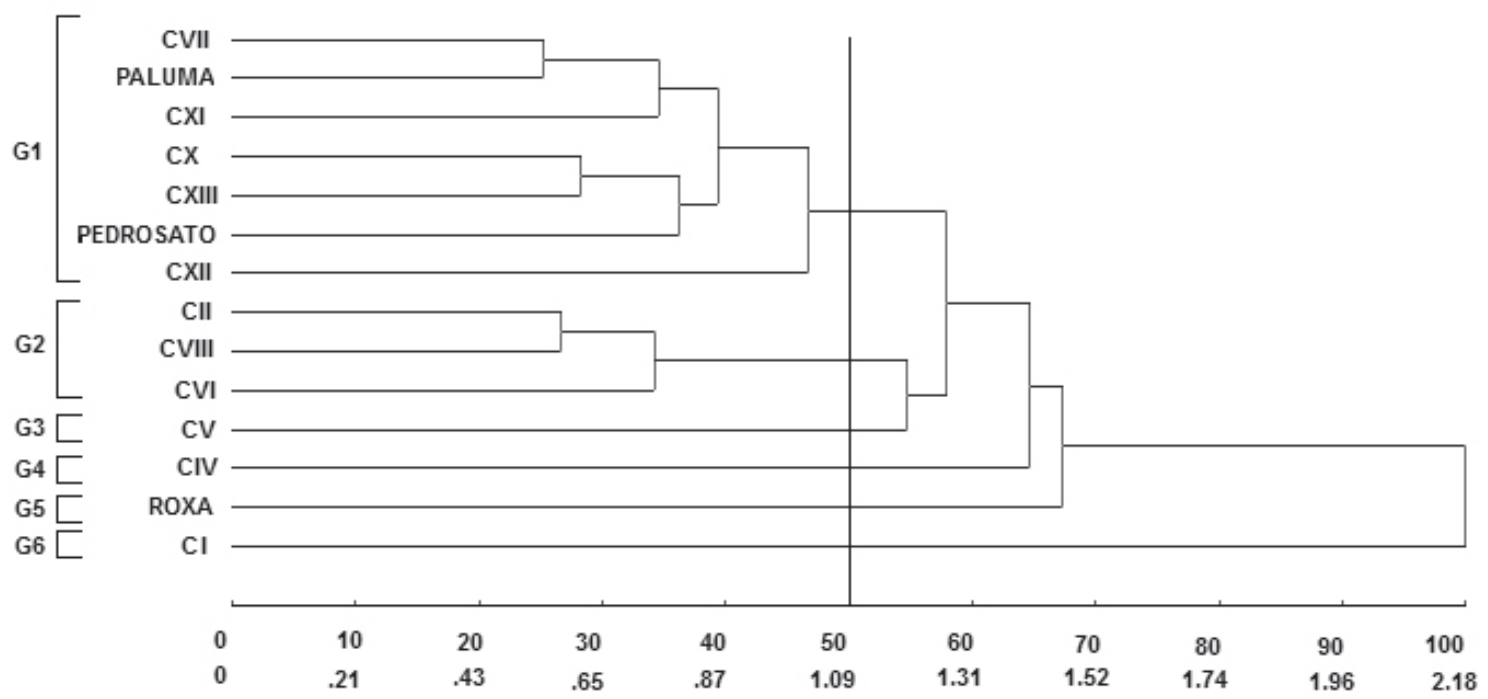

FIGURA 2- Agrupamento de 14 genótipos de Psidium guajava para caracteres quantitativos de fruto, pelo método UPGMA. $(\mathrm{C}=$ Cortibel).

TABELA3-Componentes principais obtidos da análise de sete caracteres quantitativos para Psidium guajava.

\begin{tabular}{|c|c|c|c|c|c|c|c|c|c|}
\hline \multirow{2}{*}{ Componente } & \multicolumn{7}{|c|}{ Coeficientes de Ponderação Associados } & \multirow{2}{*}{ Variância } & \multirow{2}{*}{$\begin{array}{c}\text { Variância } \\
\text { Acumulada (\%) }\end{array}$} \\
\hline & M (g) & $\mathrm{C}(\mathrm{cm})$ & Dt (cm) & Di (cm) & $\mathrm{Dt} / \mathrm{Di}$ & NL & MP (g) & & \\
\hline C & 0,4632 & 0,4451 & 4622 & 0,4139 & 0,1668 & $-0,1185$ & 0,4006 & 65,0217 & 17 \\
\hline $\mathrm{CP} 2$ & 0,0575 & 0,0502 & 0,0954 & $-0,321$ & 0,6544 & $-0,5789$ & $-0,3444$ & 24,0719 & 89,0937 \\
\hline $\mathrm{CP} 3$ & 0,087 & 0,2205 & 0,0633 & $-0,2473$ & 0,4805 & 0,7946 & $-0,1281$ & 8,3774 & 97,4711 \\
\hline $\mathrm{CP} 4$ & $-0,1002$ & $-0,6652$ & 0,1432 & $-0,0699$ & 0,3672 & 0,0405 & 0,621 & 1,6824 & 99,1536 \\
\hline CP5 & $-0,3078$ & 0,5315 & $-0,354$ & $-0,4127$ & 0,0119 & $-0,1316$ & 0,5565 & 0,6727 & 99,8263 \\
\hline CP6 & $-0,8148$ & 0,1602 & 0,3249 & 0,4041 & 0,1784 & 0,0213 & $-0,0962$ & 0,1670 & 99,9934 \\
\hline CP7 & 0,0761 & $-0,0096$ & $-0,7224$ & 0,5709 & 0,3825 & $-0,0007$ & 0,0068 & 0,0066 & 100 \\
\hline
\end{tabular}




\section{CONCLUSÕES}

1-Existe divergência entre os genótipos Cortibel e os comerciais, e variabilidade entre os genótipos Cortibel, viabilizando o uso destes materiais genéticos em programas de melhoramento.

2-O genótipo mais divergente é o CI, com o melhor desempenho para as características avaliadas, enquanto os genótipos CVIII e CIV apresentam os melhores desempenhos dentre os genótipos de polpa clara.

3-A maioria das seleções de Cortibel apresenta desempenho semelhante quanto à qualidade dos frutos aos genótipos comerciais cultivados.

\section{AGRADECIMENTOS}

Ao Conselho Nacional de Desenvolvimento Científico e Tecnológico (CNPq), à Fundação de Amparo à Pesquisa do Espírito Santo (FAPES) e à Coordenação de Aperfeiçoamento de Pessoal de Nível Superior (CAPES), pelo suporte financeiro; e também ao Sr. José e Sra. Isabel Corti e Sr. Erli Röpke, pela disponibilização do pomar.

\section{REFERÊNCIAS}

ALVES, J. E.; FREITAS, B. M. Requerimentos de polinização da goiabeira. Ciência Rural, Santa Maria, v. 37, p.1281-1286, 2007.

AZOLINNI, M.; JACOMINO, A. P.; SPOTO, M. H. F. Estádios de maturação e qualidade pós-colheita de goiabas "Pedro Sato". Revista Brasileira de Fruticultura, Jaboticabal, v. 26, n. 1, p. 29-31, 2004.

BRUNINI, M. A.; OLIVEIRA, A. L.; VARANDA, D. B. Avaliação da qualidade de polpa de goiaba 'paluma' armazenada a $-20^{\circ} \mathrm{c}$. Revista Brasileira de Fruticultura, Jaboticabal, v. 25, n. 3, p. 394396, 2003.

COSER, S. M.; FERREIRA, M. F. S.; FERREIRA, A.; MITRE, L. K.; CARVALHO, C. R.; CLARINDO, W. R. Assessment of genetic diversity in Psidium guajava L. using different approaches. Scientia Horticulturae, Amsterdam, v. 148, p. 223-229, 2012.
CRUZ, C.D. Programa genes: biometria. Viçosa: Editora UFV, 2006. 382p.

KROLOW, A. C.; SCHWENGBER, J. Avaliações físicas e químicas de morango cv. Aromas produzidos em sistema orgânico e convencional. Revista Brasileira de Agroecologia, Santa Maria, v. 2, p. 1732-1735, 2007.

LIMA, M. A. C.; ASSIS, J. S.; GONZAGA NETO, L. Caracterização dos frutos de goiabeira e seleção de cultivares na região do submédio São Francisco. Revista Brasileira de Fruticultura, Jaboticabal, v. 24, p. 273-276, 2002.

LOZANO, L. J.; PINZÓN, M. I. A.; FLÓREZ, J. E. M. Caracterización morfológica de accessiones silvestres de guayaba. Acta Agronómica, Palmira, v.58, p. 69-73, 2009.

MANICA, I.; KIST, H.; MICHELETTO, E. L.; KRAUSE, C.A. Competição entre quatro cultivares e duas seleções de goiabeira. Pesquisa Agropecuária Brasileira, Brasília, v. 33, p.1305-1313, 1998.

NIMISHA, S.; KHERWAR, D.; AJAY, K. M.; SINGH, B.; USHA, K. Molecular breeding to improve guava (Psidium guajava L.): Current status and future prospective. Scientia Horticulturae, Amsterdam, v. 164, p. 578-588, 2013.

PEREIRA, F. M.; KAVATI, R. Contribution of Brazilian scientific research in developing some of subtropical fruit. Revista Brasileira de Fruticultura, Jaboticabal, v. 33, n.1, p. 92-108, 2011.

PEREIRA, F. M.; NACHTIGAL, J. C. Goiabeira. In: BRUCKNER, C.H. (Ed.). Melhoramento de fruteiras tropicais. Viçosa: Editora UFV, 2002. p.267-289.

PEREIRA, F. M.; NACHTIGAL, J. C. Melhoramento Genético da Goiabeira. In: NATALE, W. (Ed.). Cultura da Goiaba do plantio à comercialização. São Paulo: Editora Unesp, 2009. p. 371-394.

SANABRIA, H. L.; GARCIA, M. A.; MUÑOZ, J. E.; DIAZ, H. A. Caracterizacion molecular com marcadores RAM de arboles nativos de Psidium guajava (guayaba) en el Valle del Cauca. Acta Agronomica, Palmira, v. 55, p. 27-38, 2006. 
SANTOS, C. A. F.; CASTRO, J. M. C.; SOUZA, F. F.; VILARINHO, A. A.; FERREIRA, J.; PÁDUA, F. R. F. G.; BORGES, R. M. E.; BARBIERI, R. L.; SOUZA, A. G. S.; RODRIGUES, M. A. Prospecting and morphological characterization of brazilian Psidium germplasm. Acta Horticulturae, The Hague, v. 849, p. 63-68, 2010.

SANTOS, C. A. F.; CORRÊA, L. C.; COSTA, S. R. Genetic divergence among Psidium accessions based on biochemical and agronomic variables. Crop Breeding and Applied Biotechnology, Londrina, v. 11, p. 149-156, 2011.
YUSOF, S. Physico-chemical characteristics of some guava varieties in Malaysia. Acta Horticulturae, The Hague, n.269, p.301-305, 1990. 